BNL-112593-2016-JA

\title{
Measurement of the Dewetting, Nucleation, and Deactivation Kinetics of Carbon Nanotube Population Growth by Environmental Transmission Electron Microscopy
}

\author{
Mostafa Bedewy, Viswanath Balakrishnan, Eric R. Meshot, \\ Dmitri N. Zakharov, Eric A. Stach, A. John Hart
}

Submitted to Chemistry Of Materials

June 2016

Center for Functional Nanomaterials

Brookhaven National Laboratory

\author{
U.S. Department of Energy \\ USDOE Office of Science (SC), \\ Basic Energy Sciences (BES) (SC-22)
}

Notice: This manuscript has been authored by employees of Brookhaven Science Associates, LLC under Contract No. DE-SC0012704 with the U.S. Department of Energy. The publisher by accepting the manuscript for publication acknowledges that the United States Government retains a non-exclusive, paid-up, irrevocable, world-wide license to publish or reproduce the published form of this manuscript, or allow others to do so, for United States Government purposes. 


\section{DISCLAIMER}

This report was prepared as an account of work sponsored by an agency of the United States Government. Neither the United States Government nor any agency thereof, nor any of their employees, nor any of their contractors, subcontractors, or their employees, makes any warranty, express or implied, or assumes any legal liability or responsibility for the accuracy, completeness, or any third party's use or the results of such use of any information, apparatus, product, or process disclosed, or represents that its use would not infringe privately owned rights. Reference herein to any specific commercial product, process, or service by trade name, trademark, manufacturer, or otherwise, does not necessarily constitute or imply its endorsement, recommendation, or favoring by the United States Government or any agency thereof or its contractors or subcontractors. The views and opinions of authors expressed herein do not necessarily state or reflect those of the United States Government or any agency thereof. 
1 Measurement of the Dewetting, Nucleation, and

2 Deactivation Kinetics of Carbon Nanotube

3 Population Growth by Environmental Transmission

4 Electron Microscopy

5 Mostafa Bedewy ${ }^{1,2, \dagger}$, Viswanath Balakrishnan ${ }^{1, \dagger}$, Eric R. Meshot ${ }^{3}$, Dmitri N. Zakharov ${ }^{4}$, Eric A.

6 Stach $^{4}$, A. John Hart ${ }^{1,2 *}$

$7 \quad{ }^{1}$ Department of Mechanical Engineering and Laboratory for Manufacturing and Productivity,

8 Massachusetts Institute of Technology, 77 Massachusetts Avenue, Cambridge, MA 02139, USA

$9{ }^{2}$ Department of Mechanical Engineering, University of Michigan, 2350 Hayward St. Ann Arbor,

10 MI 48109, USA

$11{ }^{3}$ Physical and Life Sciences Directorate, Lawrence Livermore National Laboratory, Livermore,

12 CA, USA.

$13{ }^{4}$ Center for Functional Nanomaterials, Brookhaven National Laboratory, Upton, NY, USA.

$14 \dagger$ Current Address: Research Laboratory of Electronics, Massachusetts Institute of Technology,

1577 Massachusetts Avenue, Cambridge, MA 02139, USA

$16 \pitchfork$ Current Address: Indian Institute of Technology, Mandi, India

$17 *$ Corresponding author, Prof. A. J. Hart, E-mail: ajhart@ mit.edu

19 KEYWORDS.

20 Carbon nanotubes, kinetics, catalysis, dewetting, electron microscopy. 


\section{ABSTRACT}

22 Understanding the collective growth of vertically aligned carbon nanotube (CNT) populations is

23 key to tailoring their properties for many applications. During the initial stages of CNT growth

24 by chemical vapor deposition (CVD), catalyst nanoparticle formation by thin-film dewetting and

25 the subsequent CNT nucleation processes dictate the CNT diameter distribution, areal density, 26 and alignment. Herein, we use in situ environmental transmission electron microscopy (E-TEM)

27 to observe the catalyst annealing, growth, and deactivation stages for a population of CNTs 28 grown from a model thin film catalyst. Complementary in situ electron diffraction (ED) and 29 TEM imaging show that during the annealing step in hydrogen, reduction of the iron oxide 30 catalyst is concomitant with changes in the thin-film morphology; complete dewetting and the 31 formation of a population of nanoparticles is only achieved upon the introduction of the carbon 32 source (acetylene). The dewetting kinetics, i.e., the appearance of distinct nanoparticles, exhibit 33 a sigmoidal (autocatalytic) curve with 95\% of all nanoparticles appearing within 6 seconds. 34 After nanoparticles form, they either nucleate CNTs or remain inactive, with incubation times 35 measured to be as small as 3.5 seconds. TEM imaging also enables observing the build-up of 36 alignment during CNT crowding. In addition, in situ electron energy loss spectroscopy (EELS) 37 shows that the collective rate of carbon accumulation decays exponentially, based on real-time 38 changes in the carbon K-edge near-edge structure. Hence, both the kinetics of catalyst formation 39 and CNT nucleation must be addressed to achieve uniform and high CNT density, and their 40 transient behavior may be a primary cause of the well-known non-uniform density of CNT 41 forests. 


\section{INTRODUCTION}

45 Understanding the collective growth process of vertically aligned carbon nanotubes (often called

46 'forests' or 'carpets') has been recognized as essential to improve their properties for

47 applications such as thermal and electrical interfaces, sensors, and laminated composites. ${ }^{1}$ This

48 is because of spatial variations in alignment and density that are now known to arise during the

49 successive stages of CNT growth; and these variations have been shown to significantly

50 influence and in some cases compromise the properties of the forest. ${ }^{2-8}$ While there have been

51 significant advances towards controlling CNT growth by chemical vapor deposition (CVD),

52 including efforts towards improving the nominal values of CNT diameter, chirality, and/or

53 density, ${ }^{9-13}$ the morphology and dimensions of CNTs in forests vary both spatially and

54 temporally during growth. Hence, there is a need to understand the successive stages of catalyst

55 activation as well as CNT nucleation and growth in order to manufacture CNT-based materials

56 with desirable and predictable morphologies and properties.

57 The collective growth process of CNT forests on substrates by CVD is known to begin with the

58 nucleation of randomly oriented CNTs from a population of catalyst nanoparticles. This is

59 followed by the build-up of alignment during the crowding stage, wherein the number density of

60 CNTs increases and the CNTs vertically align when the density exceeds a critical value, which

61 depends on the diameter, length, and interactions of the CNTs. Then, vertically aligned growth

62 proceeds with a slow decay of CNT density that results from the accumulation of deactivated

63 individual catalyst nanoparticles. Forest self-termination then ensues as the CNT forest height

64 stops increasing when the density falls below the aforementioned critical value, which was

65 computationally and experimentally determined to be on the order of $10^{9} \mathrm{CNTs} / \mathrm{cm}^{2} .14,15$ 
This collective growth and decay mechanism has been revealed largely through the use of ex situ

67 scanning electron microscopy (SEM) to measure the morphological evolution, ${ }^{16,17}$ or in situ as

68 well as ex situ small angle X-ray scattering (SAXS) to precisely map CNT density, diameter

69 distribution, and alignment across forests. ${ }^{15,18-21}$ However, owing to limitations of the time and

70 length scales of these techniques, quantitative information about the earliest period of catalyst

71 activation and CNT nucleation - where total CNT length is within a few tens of nanometers

72 distance from the substrate - is not obtained. This early stage has been interrogated by surface

73 characterization methods, such as in situ grazing-incidence SAXS (GI-SAXS) to show the

74 dynamics of particle dewetting, ${ }^{22}$ grazing incidence X-ray diffraction (GI-XRD) and electron

75 diffraction (ED) to monitor the dynamics of phase changes of the transition metal catalyst, ${ }^{23,24}$

76 and X-ray photoelectron spectroscopy (XPS) to reveal the changes in chemical state during

77 catalyst-carbon interactions. ${ }^{25,} 26$ Also, Z-Contrast scanning transmission electron microscopy

78 and optical reflectivity were used for real-time characterization of CNT nucleation density and

79 height kinetics in pulsed CNT growth. ${ }^{27-29}$ However, a single in situ technique, which can probe

80 the evolution of catalyst structure and chemistry while imaging a large CNT population during

81 the entire growth process, is still needed.

82 For CNT nucleation from Fe nanoparticle catalysts on $\mathrm{Al}_{2} \mathrm{O}_{3}$ support layers, film restructuring

83 was studied previously by in situ GI-SAXS, which demonstrated the rapid formation of

84 nanoparticles during dewetting and enabled quantitative evaluation of the statistical distribution

85 of nanoparticle sizes. ${ }^{22}$ However, the scattering signal from the particles is obscured once CNTs

86 nucleate and start crowding at a high density, making it challenging to decouple the different

87 contributions to the scattering from the particles and the CNTs. Therefore, it is challenging to use

88 grazing incidence $\mathrm{X}$-ray scattering to derive precise information regarding nanoparticle evolution 
89 during the early stages of CNT nucleation and growth. Nevertheless, both GI-SAXS and GI-

90 XRD results showed that there is an abrupt transition between tangled and aligned CNTs

91 concomitant with vertical growth and correlates with CNT density increase. ${ }^{22,30}$

92 Using in situ XPS, Hofmann et al. showed that the reduction of $\mathrm{Fe}^{3+}$ and $\mathrm{Fe}^{2+}$ to the more

93 catalytically active metallic Fe phase is in general necessary for efficient CNT nucleation from a

94 population of nanoparticles. ${ }^{31}$ On the other hand, de los Arcos et al. used in situ XPS to show

95 that the active catalyst phase can be either $\mathrm{Fe}$ or $\mathrm{FeO}$ depending on both the chemical and

96 morphological features of the buffer layer. ${ }^{32}$ In addition, XPS enabled tracking of the transition

97 from chemisorbed carbon to graphitic carbon deposition by monitoring the evolution of the core

98 carbon 1s peak as a function of time, indicating the onset of CNT nucleation by C-C bond

99 formation upon the introduction of the hydrocarbon gas precursor $\mathrm{C}_{2} \mathrm{H}_{2} \cdot{ }^{25}$ Nevertheless, the

100 limited penetration depth of XPS analysis $(\sim 2 \mathrm{~nm})$, hinders the continued monitoring of catalytic

101 activity once CNTs cover the catalyst nanoparticles, much like with GI-SAXS.

102 Using in situ ED, the activity and phase changes of the catalyst during CNT growth were also

103 studied. There, it was found that iron carbide forms upon exposure of body-centered cubic

104 (BCC) metallic iron to acetylene, and that the cementite phase $\left(\mathrm{Fe}_{3} \mathrm{C}\right)$ is the active phase

105 necessary for nucleating CNTs, while the carbon-rich Hägg phase $\left(\mathrm{Fe}_{5} \mathrm{C}_{2}\right)$ is the inactive phase. ${ }^{33}$

106 Further, complementary analysis by in situ GI-XRD demonstrated the evolution of catalyst phase

107 and showed that for FCC-rich iron catalyst $(\gamma-\mathrm{Fe})$, the metallic Fe is the active phase and carbide

108 formation is not necessary, while in the BCC-rich case ( $\alpha-\mathrm{Fe})$, carbide formation is part of the

109 growth process. ${ }^{23}$ 
111 The abovementioned studies show that individual catalyst nanoparticles can follow multiple 112 pathways during sequential exposure to annealing gases followed by hydrocarbon growth

113 precursors; this likely arises due to the inherent variability of catalyst nanoparticle sizes, phases,

114 and the presence of contaminants or other local interactions. To this end, real-time imaging of 115 catalyst restructuring and CNT nucleation by E-TEM has been used to study the atomic scale 116 mechanisms of graphitic cap formation and liftoff from dynamically deforming crystalline 117 nanoparticles, as well as to directly measure growth kinetics of individual CNTs. ${ }^{23,} 25,34-36$ 118 Nevertheless, E-TEM has not been applied to observe the formation of CNT populations and 119 their interactions during growth. Therefore, in order to assess this behavior on a population 120 basis, in situ techniques for studying the collective morphological and chemical evolution of 121 catalyst nanoparticles in proximity to each other during the early stage of growth are needed.

122 In this paper, we present the first real-time observation of the collective CNT nucleation and 123 deactivation in E-TEM by combining imaging, diffraction, and spectroscopy at the same growth 124 conditions, in order to derive the chemical and morphological population dynamics. In situ TEM 125 imaging of nanoparticle populations, with more than 200 particles in the field of view, reveals 126 the population kinetics of catalyst nanoparticle formation; ED enables analyzing the structural 127 and associated chemical changes as iron oxide reduces in the $\mathrm{H}_{2}$ environment; and electron 128 energy loss spectroscopy (EELS) is used to quantify the collective catalytic deactivation kinetics. 129 Finally, real-time imaging also shows for the first time the dynamics of bundling among CNTs 130 during crowding, leading to the buildup of alignment.

131 Our results show that there is a distribution of different oxide and metallic phases of Fe during 132 annealing, with varying proportions, likely depending on local variations of sizes, contaminants 133 or even different local interactions with the support. We find that, under the applied conditions 
134 of pressure and temperature, full reduction is not complete and nanoparticle formation by

135 dewetting is slow until $\mathrm{C}_{2} \mathrm{H}_{2}$ is introduced. The accelerated dewetting upon $\mathrm{C}_{2} \mathrm{H}_{2}$ exposure is

136 rather striking as nanoparticles suddenly appear, or "pop", into view in the E-TEM.

\section{EXPERIMENTAL SECTION}

138 Substrates used in this study were commercial $3 \mathrm{~mm}$ diameter TEM membranes (Norcada), 139 having an array of nine $100 \times 100 \mu \mathrm{m}$ windows of $30 \mathrm{~nm}$ thick silicon nitride $\left(\mathrm{Si}_{3} \mathrm{~N}_{4}\right)$ 140 membranes. Catalyst films (1 nm Fe on top of $10 \mathrm{~nm} \mathrm{Al}_{2} \mathrm{O}_{3}$ ) were deposited on these 141 membranes by sputtering (LAB 18 from Kurt J. Lesker).

142 All CNT experiments were carried out inside the FEI Titan 80-300 (Center for Functional

143 Nanomaterials at Brookhaven National Laboratory), which is a field-emission environmental 144 transmission electron microscope (E-TEM) with an objective-lens aberration corrector. Electron 145 beam acceleration voltage was kept at $300 \mathrm{kV}$. Differential pumping apertures enabled imaging 146 at relatively high pressures making this system well-suited for in situ studies of CVD growth of

147 CNTs. Process gases partial pressures were controlled by high precision leak valves. For this 148 study, a partial pressure of 40 mTorr of Hydrogen $\left(\mathrm{H}_{2}\right)$ and 10 mTorr of Acetylene $\left(\mathrm{C}_{2} \mathrm{H}_{2}\right)$ were

149 selected. Sample annealing and growth temperatures were controlled by means of single-tilt 150 heating holder, operated at $750{ }^{\circ} \mathrm{C}$. Before starting the growth experiments, a base pressure of 151 below $10^{-5}$ Torr was reached.

152 Samples were first loaded inside the E-TEM reactor (Figure 1), and the temperature is raised to 153 the $750{ }^{\circ} \mathrm{C}$ in $\mathrm{H}_{2}$ (at 40 mTorr), at rate of $100{ }^{\circ} \mathrm{C}$ per minute. After waiting at this temperature 154 for 15 minutes (to allow for the thermal stabilization of substrate and avoid sample drift during 
155 imaging), $\mathrm{C}_{2} \mathrm{H}_{2}$ is introduced so that the total pressure reaches 50 mTorr. This enables imaging

156 during the initial nucleation stage that starts with the introduction of the hydrocarbon gas.

157 EELS data collected using a Tridiem Gatan Image Filter (GIF) and were processed using the

158 Cornell Spectrum Imager (CSI) plugin for ImageJ ${ }^{37}$ and background subtraction was done using

159 a power law. In order to minimize the effect of carbon desorption from the wall of the reactor,

160 we waited for the base-pressure to drop below $10^{-5}$ Torr before starting each experiment. Also,

161 the order of shutting down an experiment can greatly impact the effect of these carbonaceous

162 species on growth. In order to reduce this effect in our experiments, we shut down the gas flow

163 valves for $\mathrm{C}_{2} \mathrm{H}_{2}$ before ramping the temperature down to ensure that the partial pressure of $\mathrm{C}_{2} \mathrm{H}_{2}$

164 is as low as possible during cooling. In general, a wait of 5 minutes at high temperature after

165 shutting the hydrocarbon gas flow was found to be enough to rid the system of the residual

166 species.

\section{RESULTS AND DISCUSSION}

168 CNT forests were grown from substrate-bound catalyst nanoparticles on an electron-transparent

169 membrane in an E-TEM microreactor at the Center for Functional Nanomaterials, Brookhaven

170 National Laboratory, shown schematically in Figure 1a. Catalyst-coated (1 nm Fe / $10 \mathrm{~nm}$

$171 \mathrm{Al}_{2} \mathrm{O}_{3}$ ) silicon nitride membrane (30 nm thick) grids were heated to $750{ }^{\circ} \mathrm{C}$ in hydrogen $(40$

172 mTorr), and then the temperature was held for 15 minutes before introducing acetylene $\left(\mathrm{C}_{2} \mathrm{H}_{2}\right)$ as

173 the hydrocarbon precursor, bringing the total pressure to 50 mTorr. As shown in Figure 1b, TEM

174 images were recorded throughout the process, with ED patterns collected during the annealing

175 stage and EELS data were collected during the growth stage. Although a high electron

176 acceleration voltage of $300 \mathrm{kV}$ was used, no structural degradation of CNT walls was observed 
177 during imaging at growth conditions even for extended periods of time exceeding 30 minutes.

178 This may be attributed to conditions of high temperature $\left(750^{\circ} \mathrm{C}\right)$ in a carbon-containing

179 atmosphere. On the other hand, when we cool down the sample and collect TEM images after

180 growth is done (ex situ), we observed structural damage in CNTs caused by the electron beam.

\section{Catalyst reduction and restructuring during annealing}

182 We find that heating in $\mathrm{H}_{2}$ causes progressive restructuring and reduction of the as-deposited thin

183 catalyst film. The ED patterns in Figure 2 have multiple continuous rings at the beginning of the

184 annealing step, which signifies diffraction from different crystalline structures that are a mixture

185 of iron oxide phases. The constant presence of rings in the ED patterns throughout the annealing

186 process indicates that at least some of the catalyst remains in a crystalline solid phase throughout

187 the $\mathrm{H}_{2}$ exposure step, even for the metallic Fe phase. The emergence of distinct reflection points

188 on the rings as time proceeds along with heating to $750{ }^{\circ} \mathrm{C}$ indicates restructuring of the

189 polycrystalline film to form larger crystallites. After holding for 107 minutes at $750{ }^{\circ} \mathrm{C}$ the

190 reduction is not complete, as evidenced by the mixture of rings corresponding to metallic Fe and

191 to oxide phases (Figure 2g). In particular, the two inner-most rings, having interplanar spacings

192 of $3.06 \AA$ and $2.62 \AA$, are larger than those found in metallic Fe phases. The outermost (sixth)

193 ring, which corresponds to the smallest spacing of $1.24 \AA$ confirms the existence of metallic Fe

194 phase. Importantly, this sixth ring emerges only after an extended dwell time in $\mathrm{H}_{2}$ at $750{ }^{\circ} \mathrm{C}$.

195 Corresponding images (Figure $2 \mathrm{~h}-\mathrm{j}$ ) taken during the same experiment indicate that reduction to

196 the metallic phase is accompanied by the formation of well-defined nanoparticles.

197 Therefore, we find that for our films, heating the iron oxide up to $750{ }^{\circ} \mathrm{C}$ in $\mathrm{H}_{2}$ at low pressure 198 (40 mTorr) and dwelling for 15 minutes was not sufficient to fully reduce the catalyst to metallic 
$199 \mathrm{Fe}^{24,31}$ In previous studies, a hot tungsten filament was used to heat the annealing and growth 200 gas up to $2000{ }^{\circ} \mathrm{C}$ in order to produce atomic hydrogen and active species for rapid catalyst

201 reduction and CNT growth. ${ }^{38,39}$ Moreover, it has been shown that a stronger reducing agent 202 such as ammonia $\left(\mathrm{NH}_{3}\right)$ was required for complete reduction of Fe to take place. ${ }^{31}$ Also, 203 hydrazine $\left(\mathrm{N}_{2} \mathrm{H}_{4}\right)$ was shown to be an efficient reducing agent compared to atomic hydrogen for

204 the complete reduction of Fe oxide. ${ }^{40}$ Hence, reduction and phase change of the catalyst are 205 dependent on the reducing gas environment, as well as the temperature, pressure and time of 206 exposure.

207 At the end of this annealing step, the catalyst film comprises elongated islands that are rather flat 208 (see Figures S1 and S2), and this film restructuring is likely driven by the growth of holes in the 209 film to minimize surface energy. ${ }^{41}$ These flat thin structures are not clearly visible in TEM 210 images (Figure 3a) at low magnification. Although a few distinct nanoparticles can be seen at 211 this point, full dewettting was observed only upon exposure to $\mathrm{C}_{2} \mathrm{H}_{2}$, as seen in Figure 3 and 212 Figure S1.

\section{Kinetics of nanoparticle formation}

214 Upon introduction of $\mathrm{C}_{2} \mathrm{H}_{2}$, the number of high-contrast nanoparticles increased rapidly within 215 several seconds, as shown in Figure 3a-f (see Video S1 and still frames in Figure S1). The 216 kinetics of this nanoparticle 'popping' phenomenon, plotted in Figure 3g, exhibits an S-shaped 217 characteristic population growth curve. These data were collected from a single location with a 218 field of view of $260 \mathrm{~nm} \times 260 \mathrm{~nm}$ containing more than 200 nanoparticles, and are well

219 described by a sigmoidal model (logistic ogive), according to the equation $n_{p}(t)=\frac{\alpha}{1+e^{-k .\left(t-\tau_{p}\right)}}$.

220 Here, $n_{p}(t)$ is the number of nanoparticles evaluated to have sufficient contrast to be counted at 
221 each point in time $t, \alpha$ is the total number of nanoparticles at the end of formation, $\tau_{p}$ is the time

222 of the midpoint of the logistic curve, and $k$ is a measure of the steepness of the curve. This

223 logistic growth model, which is also referred to as the autocatalytic model, ${ }^{42}$ fits the data well

224 with a coefficient of determination $\mathrm{R}^{2}$ of 0.999 , for the following fitting parameters: $\alpha \approx 229, \tau_{p} \approx$

2253.2 seconds, and $\mathrm{k} \approx 0.96$. At 6 seconds after $\mathrm{C}_{2} \mathrm{H}_{2}$ exposure, the kinetics reached a plateau at

226 about 230 nanoparticles in the $260 \mathrm{~nm} \times 260 \mathrm{~nm}$ field of view (Figure $\mathrm{S} 1$ ); this corresponds to $\approx$

$2273 \times 10^{11}$ particles $/ \mathrm{cm}^{2}$ and is $95 \%$ of the final value. This signifies the reduction and complete

228 dewetting of the catalyst film into fully formed nanoparticles.

229 Therefore, we can conclude that $\mathrm{C}_{2} \mathrm{H}_{2}$ promotes rapid dewetting of the catalyst film, at our

230 conditions of low pressure (50 mTorr). $\mathrm{C}_{2} \mathrm{H}_{2}$ was previously shown to reduce iron oxide at 700

$231{ }^{\circ} \mathrm{C} .{ }^{43}$ Using real-time GI-SAXS, it was shown that fast heating in the presence of a hydrocarbon

232 gas $\left(\mathrm{C}_{2} \mathrm{H}_{4}\right)$ assisted dewetting, i.e., nanoparticles formed more rapidly and at lower temperatures,

233 leading to fast nucleation of CNTs. ${ }^{22}$ In addition, it has been suggested that carbon deposits on

234 the walls of the CVD reactor promote the formation of carbon-filled nanoparticles, and thereby

235 promote dewetting. ${ }^{44}$ These results were explained by the exothermic decomposition of active

236 radicals $\left(\mathrm{CH}_{2}\right)$ on metal, which accelerate the dewetting of as-deposited catalyst films. ${ }^{44}$

237 Hence, $\mathrm{C}_{2} \mathrm{H}_{2}$ may have two effects on the dewetting process: first, it facilitates the reduction of

238 iron oxide owing to the chemical dissociation of $\mathrm{C}_{2} \mathrm{H}_{2}$ on the catalyst surface, accelerating

239 nanoparticle formation (dewetting); second, the chemisorption of $\mathrm{C}_{2} \mathrm{H}_{2}$ on the surface of the

240 catalyst is an exothermic process ${ }^{45,46}$ (enthalpy of formation of $\mathrm{C}_{2} \mathrm{H}_{2} \Delta_{\mathrm{f}} \mathrm{H}$ is $227.4 \mathrm{~kJ} / \mathrm{mol}^{47}$ ),

241 which supplies thermal energy that locally heats the surface, further promoting the mobility of Fe

242 atoms by surface diffusion. Moreover the chemisorption and dissociation of $\mathrm{C}_{2} \mathrm{H}_{2}$ on the catalyst

243 surface also produces hydrogen, which promotes further catalyst reduction and further $\mathrm{C}_{2} \mathrm{H}_{2}$ 
244 dissociation. This autocatalytic chain of chemical reactions could explain the observed sigmoid

245 popping kinetics.

\section{Kinetics of CNT nucleation}

247 Nucleation of the first CNTs is observed before dewetting is complete (i.e., while some new

248 nanoparticles have yet to appear). As seen in Figure 3g, the first CNT in the observation window

249 nucleates after about 3.5 seconds of introducing $\mathrm{C}_{2} \mathrm{H}_{2}$, which is well before the nanoparticle

250 formation kinetics plateaus, and the number of CNTs continues to increase beyond the 9 seconds

251 plotted here.

252 For the population, there is an overlap in the time distributions of particle formation and CNT

253 nucleation events, which underlies the collective catalytic activation behavior. While Figures 3a-

254 g represent a global perspective of particle activation and CNT nucleation, Figures 3h-k highlight

255 the local picture, showing the formation of one nanoparticle followed by the nucleation of a CNT

256 from the same nanoparticle within a time frame of less than 2 seconds. It is likely that within the

257 population there is a variation of incubation times between the time each nanoparticle forms and

258 the nucleation of a CNT from the same nanoparticle. While this kind of variation is a topic of

259 ongoing research beyond the scope of the current study, we can identify a minimum value for the

260 incubation time (i.e., time from formation of first nanoparticle after $\mathrm{C}_{2} \mathrm{H}_{2}$ to nucleation of first

261 CNT) to be within 4 seconds.

262 This insight into the incubation time for CNT nucleation complements our previous results from

263 in situ GI-SAXS for atmospheric pressure CVD of CNTs, which showed more than 15 seconds

264 for a detectable change in the scattering pattern (due to CNTs) to be visible after introducing the

265 hydrocarbon precursor. 
266 In previous work, it was inferred from the mass kinetics of CNT population growth in 267 atmospheric-pressure CVD that there is a time distribution of CNT nucleation. The population

268 growth dynamics were shown to follow an S-shaped curve, ${ }^{15,49}$ which we have previously 269 described using the asymmetric Gompertz model of population growth. ${ }^{15,50}$ The scatter in both 270 the time of forming nanoparticles (popping) and the time of CNT nucleation that we show in the 271 present study contributes to explaining the early part of the S-curve, in which CNT density 272 increases during the crowding stage. The S-shaped kinetics of CNT nucleation and growth was 273 previously discussed in the context of an autocatalytic model, in which a sufficient flux of $\mathrm{C}_{2} \mathrm{H}_{2}$ 274 is needed for high density CNT nucleation in coordinated growth. ${ }^{29}$ Our finding of S-shaped 275 popping kinetics that temporally overlap with the S-shaped CNT nucleation kinetics is therefore 276 important to the emergence of the CNT population. We can expect these kinetics to depend on 277 the flux and chemistry of the precursor gas.

\section{Carbon accumulation kinetics from EELS}

279 To complement the morphological data from imaging of catalyst formation and CNT nucleation, 280 time-resolved EELS spectra were collected simultaneously upon exposure to $\mathrm{C}_{2} \mathrm{H}_{2}$ in a separate 281 but otherwise identical experiment. This allowed us to quantify the accumulation of carbon at 282 the catalyst versus time for the same growth conditions. Upon introducing $\mathrm{C}_{2} \mathrm{H}_{2}$, the carbon $\mathrm{K}$ 283 edge intensity increases (Figure 4a), showing changes in the near-edge structure, while the 284 nitrogen K-edge of the $\mathrm{Si}_{3} \mathrm{~N}_{4}$ membrane remains largely unchanged for the same time scale of 285 observation (Figure S3). The peak at around $284 \mathrm{eV}$ is in the expected position for the $1 \mathrm{~s}-\pi^{*}$ 286 transition, while multiple peaks in the range of $290-310 \mathrm{eV}$ match the $1 \mathrm{~s}-\sigma^{*}$ transition. These

287 peaks are signatures of $s p^{2}$-hybridized carbon in graphitic accumulation both on catalyst 288 nanoparticles and in growing CNTs. ${ }^{51,52}$ The spectra shown in Figure 4a are plotted after 
289 background subtraction using a power law (see Figure S4). Notably, the time between each

290 EELS spectrum is a few seconds. Hence, it was not possible to capture the evolution of EELS

291 spectra during the initial few seconds of dewetting and CNT nucleation, which in its entirety is

292 less than 10 seconds in duration.

293 Previously, spectroscopy techniques were used to infer the real-time collective kinetics of CNT

294 growth, by integrating the area under the G-band in Raman Spectroscopy. ${ }^{49,53-55}$ In the present

295 work, we use the strength of the carbon K-edge peaks in EELS as an indication of the CNT

296 growth kinetics, i.e., the kinetics of accumulation of graphitic carbon after introducing $\mathrm{C}_{2} \mathrm{H}_{2}$.

297 The time-evolution of the $\pi^{*}$ peak area (integration in the range over a width of only $6 \mathrm{eV}$ around

298 the peak) is plotted in Figure 4b, and it exhibits a sublinear curve that captures the collective

299 growth deactivation kinetics. We fit this data with an exponential decay relationship representing

300 the accumulating mass of carbon on the substrate, $m(t)=\beta \tau_{0}\left(1-e^{-t / \tau_{c}}\right)$. Here, $\beta$ represents a

301 measure for the initial rate of carbon accumulation and $\tau_{c}$ represents a measure for the

302 characteristic catalytic lifetime. Importantly, this exponential decay kinetics represent the

303 collective growth of a population of CNTs, which likely exhibit a variation in catalytic activity

304 and lifetimes among individual catalyst nanoparticles.

305 We find that the catalytic lifetime $\tau_{c} \approx 6.1$ minutes, which is dependent on the particular

306 conditions of the experiment. Previous studies of CNT growth under pressures ranging from

307 vacuum to atmosphere show that the coupling of the carbon source chemistry, pressure, and

308 temperature influence the CNT growth rate and lifetime. ${ }^{56}$ For example, atmospheric pressure

309 CNT growth with the same catalyst system used here typically gives a lifetime (i.e., time of

310 collective termination of forest growth) of 15-30 minutes. 
311 Figure $\mathrm{S} 5$ shows the dense population of CNTs at 27.5 minutes after $\mathrm{C}_{2} \mathrm{H}_{2}$ exposure, for the same

312 experiment that produced the EELS results in Figure 4. In addition, Raman spectroscopy

313 performed ex situ on the same sample after the growth experiment (Figure S6) shows a G/D ratio

314 of 5.8 and clearly defined radial breathing modes (RBM), indicating highly graphitized CNTs

315 and the presence of single-walled CNTs, respectively.

316 The low intensity of the carbon K-edge seen in Figure 4a before the introduction of $\mathrm{C}_{2} \mathrm{H}_{2}$ is

317 attributed to the presence of organic contaminants on the substrate, as well as the possible

318 desorption of carbonaceous species into the gas phase from the walls of the microreactor.

319 Regardless, because this peak does not coincide with the $1 \mathrm{~s}-\pi^{*}$, it is inconsequential to

320 integration of the $1 \mathrm{~s}-\pi^{*}$ peak.

\section{CNT self-organization and growth termination}

322 As shown in Figure 3g, at 9 seconds, 8 CNTs are growing in the $260 \mathrm{~nm} \times 260 \mathrm{~nm}$ area of study,

323 which is higher than the approximate threshold value of $\approx 10^{9} \mathrm{CNTs} / \mathrm{cm}^{2}$ for self-alignment,

324 previously determined. ${ }^{14}$ Figure 5 shows TEM images of CNT population growth following the

325 early nucleation stage. Since, the density of growing CNTs has surpassed the threshold, self-

326 organization into the vertical orientation is induced by crowding of adjacent CNTs, as seen in

327 Figure $5 \mathrm{~b}$ after 7.5 minutes. These images show CNT bundles, as well as the circular contrast

328 arising from the cross-sectional view of vertically aligned CNTs. Figure $5 \mathrm{c}$ shows a dense CNT

329 carpet after 27.6 minutes of exposure to $\mathrm{C}_{2} \mathrm{H}_{2}$. These observations confirm that the collective

330 deactivation kinetics, obtained from EELS, represent the growth of vertically aligned CNTs.

331 Figure 5 also shows some increase in the diameter of the nanoparticles with time, which could be

332 attributed to nanoparticle size evolution over time by Ostwald ripening. ${ }^{39}$ 
333 Importantly, only a fraction of nanoparticles become active and bear CNTs $(\approx 1.3 \%$ at 5 seconds, $334 \approx 2 \%$ at 7 seconds, and $\approx 3.5 \%$ at 9 seconds), while the rest of the nanoparticles are mostly found 335 to be encapsulated by graphitic carbon, as shown by an in situ image in Figure 6a. After 336 dewetting, we find that each particle forms a cap that lifts into a growing CNT, or becomes fully 337 encapsulated with graphitic overcoating layers. In previous work on atmospheric-pressure 338 growth of CNTs using the same catalyst, we estimated that fewer than $12 \%$ of nanoparticles 339 grow CNTs. ${ }^{15}$

340 While the post-growth catalyst encapsulation could arise due to decreased solubility of $\mathrm{C}$ in $\mathrm{Fe}$

341 during cooling, the observed encapsulation at growth temperature indicates that graphitic 342 encapsulation is a possible alternate pathway that renders catalyst particles incapable of forming

343 CNTs. Further research is required to fully understand the critical factors controlling the fate of 344 each nanoparticle in a large population. Nevertheless, our analysis after growth termination 345 (after about 30 minutes of growth) of the reciprocal space images for HR-TEM of individual 346 nanoparticles by fast Fourier transform (FFT) shows that many particles are $\mathrm{Fe}_{3} \mathrm{C}$ phase, as 347 shown in Figure 6b.

348 The kinetic behavior of each CNT is likely to be subject to a distribution, which governs the 349 collective kinetics of the entire film of CNTs. It was previously suggested that minute organic 350 contaminants from typical film processing could have a significant impact on whether a BCC or 351 FCC Fe phase is formed. ${ }^{23}$ This phenomenon may also be coupled to the reported benefit of 352 oxidizing additives to the CVD atmosphere, such as $\mathrm{H}_{2} \mathrm{O}$, to reactivate or prevent deactivation of 353 catalytic nanoparticles by etching away the overcoating carbon. ${ }^{39,57}$ 
354 The above investigation of low pressure CNT growth inside the E-TEM allow us to paint a 355 detailed picture of the successive stages of collective CNT nucleation, growth, and deactivation, 356 as shown schematically in Figure 7. As indicated by in situ ED and TEM (Figure 2), our as357 deposited catalyst film is a mixture of different iron oxide phases and it is structured as planar 358 islands during annealing in hydrogen. Upon introducing $\mathrm{C}_{2} \mathrm{H}_{2}$, well-defined nanoparticles 359 rapidly form by dewetting, as seen from TEM images in Figure 3. EELS spectroscopy was used 360 to infer the kinetics of carbon accumulation during growth, which exhibits exponential 361 deactivation, as shown in Figure 4. A few seconds after introducing $\mathrm{C}_{2} \mathrm{H}_{2}$, the number of CNTs 362 increases and the CNTs grow longer and start interacting with each other. This crowding leads 363 to the formation of bundles, and the self-supporting vertical alignment emerges owing to the 364 mechanical coupling between CNTs in contact (Figure 5). This coordinated growth proceeds 365 until the progressive deactivation of catalytic nanoparticles leads ultimately to growth 366 termination. ${ }^{14,58}$ Particle coarsening by Ostwald ripening also proceeds during CNT growth, 367 which can adversely affect growth. Finally, graphitic encapsulation of inactive nanoparticles is 368 shown from high-magnification TEM images in Figure 6.

369 Previously, various low-pressure conditions have been used to synthesize vertically aligned 370 CNTs by CVD. 5, 11, 56, 59 Although all data in the present study are collected at the same 371 conditions of temperature, pressure, and gas environment, our findings directly elucidate the 372 growth mechanism and kinetics of CNT growth by CVD at low pressure (50 mTorr). Notably, 373 this pressure is a few orders of magnitudes higher than the pressure typically needed for XPS, 374 which has previously been used to investigate CNT growth in situ. ${ }^{25,}{ }^{32}$ Further, the kinetics of 375 CNT growth at low pressure may be extrapolated to higher pressures. ${ }^{56}$ Wirth et al. determined 376 that the vertical growth rate of aligned CNTs followed a power law relationship of $\mathrm{P}^{0.61}$, where $\mathrm{P}$ 
377 is the partial pressure of the carbon precursor $\left(\mathrm{C}_{2} \mathrm{H}_{2}\right)$. This relationship was interpreted based on

378 successive reactions of adsorption/dissociation of acetylene followed by atomic carbon diffusion

379 to growing CNTs.

\section{CONCLUSIONS}

381 We presented a characterization methodology based on E-TEM that quantitatively reveals the 382 dynamics of collective nanoparticle formation, CNT nucleation, and catalytic deactivation in 383 CVD, by combining TEM, ED, and EELS techniques. Our findings of sigmoidal dewetting 384 kinetics and time-varying CNT nucleation highlight the importance of the time distribution of 385 catalyst activation times in governing the uniformity of CNT forests. Therefore, further research 386 is needed on this topic in order to establish ideally uniform and dense CNT forests. Also, our 387 methodology can aid the discovery of new catalysts and reaction conditions for CNT growth, 388 including exploring the roles of additives and dynamic changes of process parameters such as 389 temperature and gas atmosphere.

\section{ACKNOWLEDGEMENTS}

391 The authors thank Erik Polsen and Fabrice Laye from the University of Michigan for their help 392 in preparing for the experiments. Financial support was provided by the Department of Energy 393 Office of Basic Sciences under award DE-SC0004927. E-TEM work was carried out at the 394 Center for Functional Nanomaterials, Brookhaven National Laboratory, which is supported by 395 the U.S. Department of Energy, Office of Basic Energy Sciences, under Contract No. DE-

396 SC0012704. A portion of this work was performed under the auspices of the U.S. Department of 397 Energy by Lawrence Livermore National Laboratory under Contract DE-AC52-07NA27344. 
Catalyst thin films were deposited in the Lurie Nanofabrication Facility (LNF) at the University

of Michigan in Ann Arbor, a member of the National Nanotechnology Infrastructure Network.

SUPPORTING INFORMATION AVAILABLE: Video showing nanoparticle dewetting and

401 CNT nucleation upon introduction $\mathrm{C}_{2} \mathrm{H}_{2}$. TEM images showing the morphology of the catalyst

402 after heating to $750{ }^{\circ} \mathrm{C}$ and dwelling for 15 minutes (immediately before introducing $\mathrm{C}_{2} \mathrm{H}_{2}$ ).

403 Extended TEM images for the time-evolution of nanoparticle formation after introducing $\mathrm{C}_{2} \mathrm{H}_{2}$.

404 The power law fit and background subtraction for EELS spectra. Time evolution of the area

405 under the nitrogen K-edge peak from EELS spectra. TEM images taken after about 27.5 minutes

406 of growth on the same sample, from which all the EELS spectra are collected. Ex situ Raman

407 spectroscopy results for CNTs grown inside the E-TEM system. This material is available free

408 of charge via the Internet at http://pubs.acs.org

\section{REFERENCES}

$410 \quad$ 1. De Volder, M. F. L.; Tawfick, S. H.; Baughman, R. H.; Hart, A. J., Carbon Nanotubes:

411 Present and Future Commercial Applications. Science 2013, 339, (6119), 535-539.

$412 \quad 2 . \quad$ Puretzky, A. A.; Geohegan, D. B.; Jesse, S.; Ivanov, I. N.; Eres, G., In situ measurements 413 and modeling of carbon nanotube array growth kinetics during chemical vapor deposition.

414 Applied Physics a-Materials Science \& Processing 2005, 81, (2), 223-240.

415 3. Futaba, D. N.; Hata, K.; Namai, T.; Yamada, T.; Mizuno, K.; Hayamizu, Y.; Yumura, 416 M.; Iijima, S., 84\% Catalyst activity of water-assisted growth of single walled carbon nanotube 417 forest characterization by a statistical and macroscopic approach. Journal of Physical Chemistry 418 B 2006, 110, (15), 8035-8038.

419 4. $\quad$ Noda, S.; Hasegawa, K.; Sugime, H.; Kakehi, K.; Zhang, Z. Y.; Maruyama, S.; 420 Yamaguchi, Y., Millimeter-thick single-walled carbon nanotube forests: Hidden role of catalyst 421 support. Japanese Journal of Applied Physics Part 2-Letters \& Express Letters 2007, 46, (17422 19), L399-L401.

$423 \quad 5 . \quad$ Einarsson, E.; Murakami, Y.; Kadowaki, M.; Maruyama, S., Growth dynamics of 424 vertically aligned single-walled carbon nanotubes from in situ measurements. Carbon 2008, 46, 425 (6), 923-930. 
6. Wirth, C. T.; Zhang, C.; Zhong, G. F.; Hofmann, S.; Robertson, J., Diffusion- and Reaction-Limited Growth of Carbon Nanotube Forests. Acs Nano 2009, 3, (11), 3560-3566.

428 7. Vinten, P.; Lefebvre, J.; Finnie, P., Kinetic critical temperature and optimized chemical 429 vapor deposition growth of carbon nanotubes. Chemical Physics Letters 2009, 469, (4-6), 293430297.

431 8. Amama, P. B.; Pint, C. L.; Kim, S. M.; McJilton, L.; Eyink, K. G.; Stach, E. A.; Hauge, 432 R. H.; Maruyama, B., Influence of Alumina Type on the Evolution and Activity of Alumina433 Supported Fe Catalysts in Single-Walled Carbon Nanotube Carpet Growth. Acs Nano 2010, 4 , 434 (2), 895-904.

435 9. Futaba, D. N.; Goto, J.; Yasuda, S.; Yamada, T.; Yumura, M.; Hata, K., General Rules 436 Governing the Highly Efficient Growth of Carbon Nanotubes. Advanced Materials 2009, 9999, 437 (9999), NA.

438 10. Hasegawa, K.; Noda, S., Diameter Increase in Millimeter-Tall Vertically Aligned Single439 Walled Carbon Nanotubes during Growth. Applied Physics Express 2010, 3, (4).

440 11. Zhong, G.; Warner, J. H.; Fouquet, M.; Robertson, A. W.; Chen, B.; Robertson, J., 441 Growth of Ultrahigh Density Single-Walled Carbon Nanotube Forests by Improved Catalyst 442 Design. ACS Nano 2012, 6, (4), 2893-2903.

443 12. Youn, S. K.; Yazdani, N.; Patscheider, J.; Park, H. G., Facile diameter control of 444 vertically aligned, narrow single-walled carbon nanotubes. RSC Advances 2013, 3, (5), 14344451441.

13. Sanchez-Valencia, J. R.; Dienel, T.; Groning, O.; Shorubalko, I.; Mueller, A.; Jansen, M.; Amsharov, K.; Ruffieux, P.; Fasel, R., Controlled synthesis of single-chirality carbon nanotubes. 448 2014, 512, (7512), 61-64.

449 14. Bedewy, M.; Meshot, E.; Guo, H.; Verploegen, E.; Lu, W.; Hart, A., Collective 450 Mechanism for the Evolution and Self-Termination of Vertically Aligned Carbon Nanotube 451 Growth. Journal of Physical Chemistry C 2009, 113, (48), 20576-20582.

452 15. Bedewy, M.; Meshot, E. R.; Reinker, M. J.; Hart, A. J., Population Growth Dynamics of 453 Carbon Nanotubes. Acs Nano 2011, 5, (11), 8974-8989.

454 16. Zhu, L. B.; Hess, D. W.; Wong, C. P., Monitoring carbon nanotube growth by formation 455 of nanotube stacks and investigation of the diffusion-controlled kinetics. Journal of Physical 456 Chemistry B 2006, 110, (11), 5445-5449.

457 17. Finnie, P. V. a. P. M. a. J. L. a. P., Distinct termination morphologies for vertically 458 aligned carbon nanotube forests. Nanotechnology 2010, 21, (3), 035603.

459 18. Wang, B. N.; Bennett, R. D.; Verploegen, E.; Hart, A. J.; Cohen, R. E., Quantitative 460 characterization of the morphology of multiwall carbon nanotube films by small-angle X-ray 461 scattering. Journal of Physical Chemistry C 2007, 111, (16), 5859-5865. 
462

463

464

465

466

467

468

469

470

471

472

473

474

475

476

477

478

479

19. Meshot, E. R.; Hart, A. J., Abrupt self-termination of vertically aligned carbon nanotube growth. Applied Physics Letters 2008, 92, (11).

20. Meshot, E. R.; Plata, D. L.; Tawfick, S.; Zhang, Y. Y.; Verploegen, E. A.; Hart, A. J., Engineering Vertically Aligned Carbon Nanotube Growth by Decoupled Thermal Treatment of Precursor and Catalyst. Acs Nano 2009, 3, (9), 2477-2486.

21. Meshot, E.; Bedewy, M.; Lyons, K.; Woll, A.; Juggernauth, K.; Tawfick, S.; Hart, A., Measuring the lengthening kinetics of aligned nanostructures by spatiotemporal correlation of height and orientation. Nanoscale 2010, 2, (6), 896-900.

22. Meshot, E. R.; Verploegen, E.; Bedewy, M.; Tawfick, S.; Woll, A. R.; Green, K. S.; Hromalik, M.; Koerner, L. J.; Philipp, H. T.; Tate, M. W.; Gruner, S. M.; Hart, A. J., High-speed in situ X-ray scattering of carbon nanotube film nucleation and self-organization. ACS Nano 2012, 6, (6), 5091-5101.

23. Wirth, C. T.; Bayer, B. C.; Gamalski, A. D.; Esconjauregui, S.; Weatherup, R. S.; Ducati, C.; Baehtz, C.; Robertson, J.; Hofmann, S., The Phase of Iron Catalyst Nanoparticles during Carbon Nanotube Growth. Chemistry of Materials 2012, 24, (24), 4633-4640.

24. Sharma, R.; Moore, E.; Rez, P.; Treacy, M. M. J., Site-Specific Fabrication of Fe Particles for Carbon Nanotube Growth. Nano Letters 2009, 9, (2), 689-694.

25. Hofmann, S.; Sharma, R.; Ducati, C.; Du, G.; Mattevi, C.; Cepek, C.; Cantoro, M.; Pisana, S.; Parvez, A.; Cervantes-Sodi, F.; Ferrari, A. C.; Dunin-Borkowski, R.; Lizzit, S.; Petaccia, L.; Goldoni, A.; Robertson, J., In situ observations of catalyst dynamics during surfacebound carbon nanotube nucleation. Nano Letters 2007, 7, (3), 602-608.

26. Mattevi, C.; Wirth, C. T.; Hofmann, S.; Blume, R.; Cantoro, M.; Ducati, C.; Cepek, C.; Knop-Gericke, A.; Milne, S.; Castellarin-Cudia, C.; Dolafi, S.; Goldoni, A.; Schloegl, R.; Robertson, J., In-situ X-ray photoelectron spectroscopy study of catalyst-support interactions and growth of carbon nanotube forests. Journal of Physical Chemistry C 2008, 112, (32), 1220712213.

27. Jackson, J. J.; Puretzky, A. A.; More, K. L.; Rouleau, C. M.; Eres, G.; Geohegan, D. B., Pulsed Growth of Vertically Aligned Nanotube Arrays with Variable Density. ACS Nano 2010, 4, (12), 7573-7581.

28. Geohegan, D. B.; Puretzky, A. A.; Jackson, J. J.; Rouleau, C. M.; Eres, G.; More, K. L., Flux-Dependent Growth Kinetics and Diameter Selectivity in Single-Wall Carbon Nanotube Arrays. ACS Nano 2011, 5, (10), 8311-8321.

29. Puretzky, A. A.; Geohegan, D. B.; Jackson, J. J.; Pannala, S.; Eres, G.; Rouleau, C. M.; More, K. L.; Thonnard, N.; Readle, J. D., Incremental growth of short SWNT arrays by pulsed chemical vapor deposition. Small 2012, 8, (10), 1534-42.

30. Landois, P.; Pinault, M.; Rouzière, S.; Porterat, D.; Mocuta, C.; Elkaim, E.; MayneL'Hermite, M.; Launois, P., In situ time resolved wide angle X-ray diffraction study of nanotube 
carpet growth: Nature of catalyst particles and progressive nanotube alignment. 2015, 87, 246256.

501 31. Hofmann, S.; Blume, R.; Wirth, C. T.; Cantoro, M.; Sharma, R.; Ducati, C.; Hävecker, 502 M.; Zafeiratos, S.; Schnoerch, P.; Oestereich, A.; Teschner, D.; Albrecht, M.; Knop-Gericke, A.; 503 Schlögl, R.; Robertson, J., State of Transition Metal Catalysts During Carbon Nanotube Growth. 504 2009, 113, (5), 1648-1656.

505 32. de los Arcos, T.; Garnier, M. G.; Seo, J. W.; Oelhafen, P.; Thommen, V.; Mathys, D., 506 The Influence of Catalyst Chemical State and Morphology on Carbon Nanotube Growth. The 507 Journal of Physical Chemistry B 2004, 108, (23), 7728-7734.

33. Mazzucco, S.; Wang, Y.; Tanase, M.; Picher, M.; Li, K.; Wu, Z.; Irle, S.; Sharma, R., Direct evidence of active and inactive phases of Fe catalyst nanoparticles for carbon nanotube formation. 2014, 319, 54-60.

34. Lin, M.; Tan, J. P. Y.; Boothroyd, C.; Loh, K. P.; Tok, E. S.; Foo, Y. L., Direct observation of single-walled carbon nanotube growth at the atomistic scale. Nano Letters 2006,

$5136,(3), 449-452$.

514 35. Yoshida, H.; Takeda, S.; Uchiyama, T.; Kohno, H.; Homma, Y., Atomic-Scale In-situ 515 Observation of Carbon Nanotube Growth from Solid State Iron Carbide Nanoparticles. Nano 516 Letters 2008, 8, (7), 2082-2086.

517 36. Moseler, M.; Cervantes-Sodi, F.; Hofmann, S.; Csanyi, G.; Ferrari, A. C., Dynamic 518 Catalyst Restructuring during Carbon Nanotube Growth. Acs Nano 2010, 4, (12), 7587-7595.

519 37. Cueva, P.; Hovden, R.; Mundy, J. A.; Xin, H. L.; Muller, D. A., Data Processing for 520 Atomic Resolution Electron Energy Loss Spectroscopy. Microscopy and Microanalysis 2012, $521 \quad 18,(04), 667-675$.

$522 \quad 38 . \quad$ Xu, Y.-Q.; Flor, E.; Schmidt, H.; Smalley, R. E.; Hauge, R. H., Effects of atomic 523 hydrogen and active carbon species in $1 \mathrm{~mm}$ vertically aligned single-walled carbon nanotube 524 growth. Applied Physics Letters 2006, 89, (12), 123116.

525 39. Amama, P. B.; Pint, C. L.; McJilton, L.; Kim, S. M.; Stach, E. A.; Murray, P. T.; Hauge, 526 R. H.; Maruyama, B., Role of Water in Super Growth of Single-Walled Carbon Nanotube 527 Carpets. Nano Letters 2009, 9, (1), 44-49.

528 40. Pint, C. L.; Kim, S. M.; Stach, E. A.; Hauge, R. H., Rapid and Scalable Reduction of 529 Dense Surface-Supported Metal-Oxide Catalyst with Hydrazine Vapor. ACS Nano 2009, 3, (7), 530 1897-1905.

531 41. Thompson, C. V., Solid-State Dewetting of Thin Films. Annual Review of Materials 532 Research 2012, 42, 399-734.

533 42. Burnham, A. K., Use and misuse of logistic equations for modeling chemical kinetics. 534 Journal of Thermal Analysis and Calorimetry 2015, 1-10. 
43. Kenji Nishimura and Nobuharu Okazaki and Lujun Pan and Yoshikazu, N., In Situ Study of Iron Catalysts for Carbon Nanotube Growth Using X-Ray Diffraction Analysis. Japanese Journal of Applied Physics 2004, 43, (4A), L471.

44. Liu, K.; Liu, P.; Jiang, K.; Fan, S., Effect of carbon deposits on the reactor wall during the growth of multi-walled carbon nanotube arrays. 2007, 45, (12), 2379-2387.

45. Baker, R. T. K.; Barber, M. A.; Harris, P. S.; Feates, F. S.; Waite, R. J., Nucleation and growth of carbon deposits from the nickel catalyzed decomposition of acetylene. 1972, 26, (1), 51-62.

46. Harutyunyan, A. R.; Kuznetsov, O. A.; Brooks, C. J.; Mora, E.; Chen, G., Thermodynamics behind Carbon Nanotube Growth via Endothermic Catalytic Decomposition Reaction. ACS Nano 2009, 3, (2), 379-385.

\section{Handbook of Chemistry \& Physics. CRC: 2015.}

48. Viswanath, B.; Bedewy, M.; Meshot, E.; Pattinson, S.; Zakharov, D.; Stach, E.; Hart, A. J., In situ TEM observation of self-organization and mechanical competition in carbon nanotube population growth. In In preparation.

49. Latorre, N.; Romeo, E.; Cazana, F.; Ubieto, T.; Royo, C.; Villacampa, J. J.; Monzon, A., Carbon Nanotube Growth by Catalytic Chemical Vapor Deposition: A Phenomenological Kinetic Model. Journal of Physical Chemistry C 2010, 114, (11), 4773-4782.

50. Bedewy, M.; Meshot, E. R.; Hart, A. J., Diameter-dependent kinetics of activation and deactivation in carbon nanotube population growth. 2012, 50, (14), 5106-5116.

51. Ajayan, P. M.; Ebbesen, T. W., Nanometre-size tubes of carbon. Reports on Progress in Physics 1997, 60, (10), 1025-1062.

52. Suenaga, K.; Sandre, E.; Colliex, C.; Pickard, C. J.; Kataura, H.; Iijima, S., Electron energy-loss spectroscopy of electron states in isolated carbon nanostructures. Physical Review $B$ 2001, 63, (16).

53. Picher, M.; Anglaret, E.; Arenal, R.; Jourdain, V., Self-Deactivation of Single-Walled Carbon Nanotube Growth Studied by in Situ Raman Measurements. Nano Letters 2009, 9, (2), 542-547.

54. Chiashi, S.; Kohno, M.; Takata, Y.; Maruyama, S., Localized synthesis of single-walled carbon nanotubes on silicon substrates by a laser heating catalytic CVD. In Cola'05: 8th International Conference on Laser Ablation, Hess, W. P.; Herman, P. R.; Bauerle, D.; Koinuma, H., Eds. 2007; Vol. 59, pp 155-158.

55. Li-Pook-Than, A.; Lefebvre, J.; Finnie, P., Phases of Carbon Nanotube Growth and Population Evolution from in Situ Raman Spectroscopy during Chemical Vapor Deposition. Journal of Physical Chemistry C 2010, 114, (25), 11018-11025. 
$570 \quad$ 56. Wirth, C. T.; Zhang, C.; Zhong, G.; Hofmann, S.; Robertson, J., Diffusion- and Reaction571 Limited Growth of Carbon Nanotube Forests. ACS Nano 2009, 3, (11), 3560-3566.

572 57. Zhang, Y. Y.; Gregoire, J. M.; van Dover, R. B.; Hart, A. J., Ethanol-Promoted High573 Yield Growth of Few-Walled Carbon Nanotubes. Journal of Physical Chemistry C 2010, 114, 574 (14), 6389-6395.

575 58. Bedewy, M.; Hart, A. J., Mechanical coupling limits the density and quality of self576 organized carbon nanotube growth. Nanoscale 2013, 5, (7), 2928-2937.

577 59. Chhowalla, M.; Teo, K. B. K.; Ducati, C.; Rupesinghe, N. L.; Amaratunga, G. A. J.; 578 Ferrari, A. C.; Roy, D.; Robertson, J.; Milne, W. I., Growth process conditions of vertically 579 aligned carbon nanotubes using plasma enhanced chemical vapor deposition. Journal of Applied $580 \quad$ Physics 2001, 90, (10), 5308-5317. 

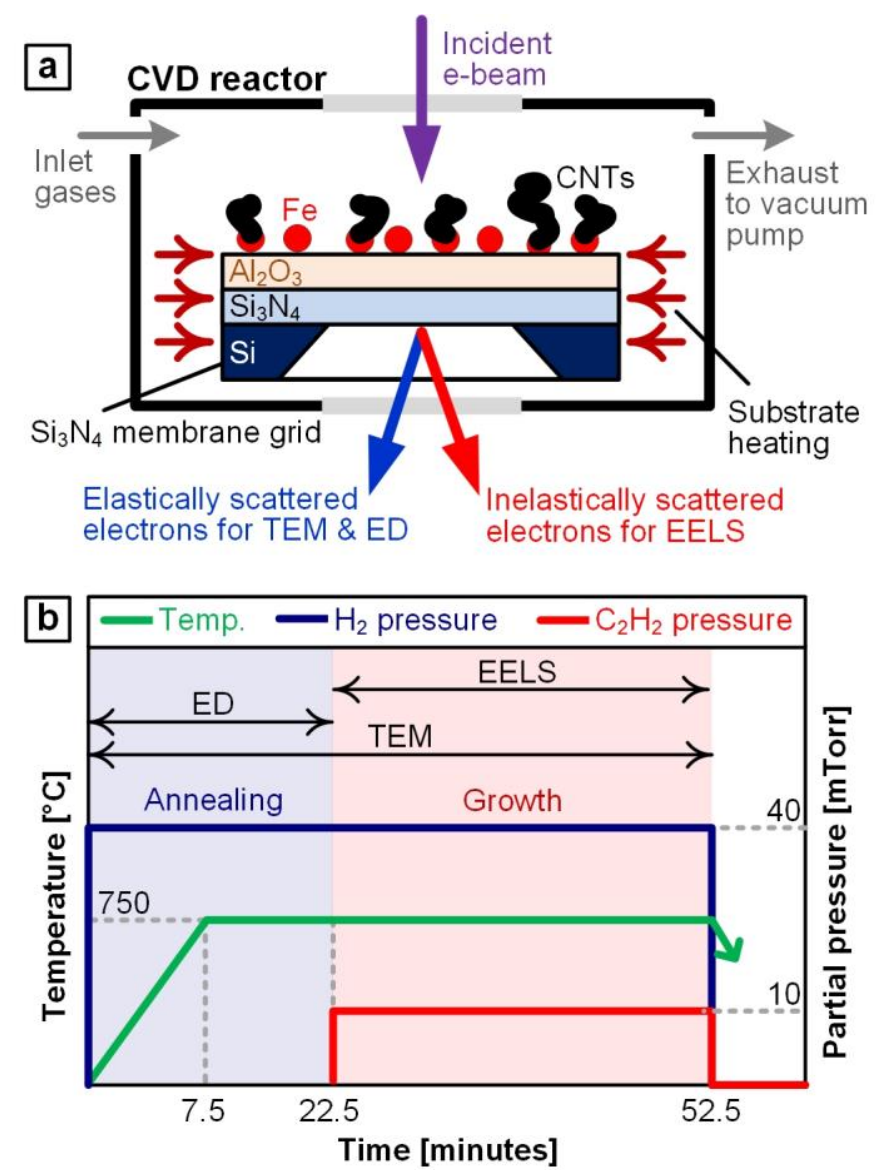

584

585 Figure 1. (a) Schematic of the CVD microreactor for CNT growth inside E-TEM, using $586 \mathrm{Fe}_{\mathrm{Al}} \mathrm{O}_{3}$ thin film deposited on silicon nitride membranes, and complementary analysis 587 techniques used. (b) Growth recipe showing the temperature profile and the partial pressures of 588 both $\mathrm{H}_{2}$ and $\mathrm{C}_{2} \mathrm{H}_{2}$ during growth, along with arrows showing the timelines for collected TEM, 589 ED, and EELS measurements.

590 

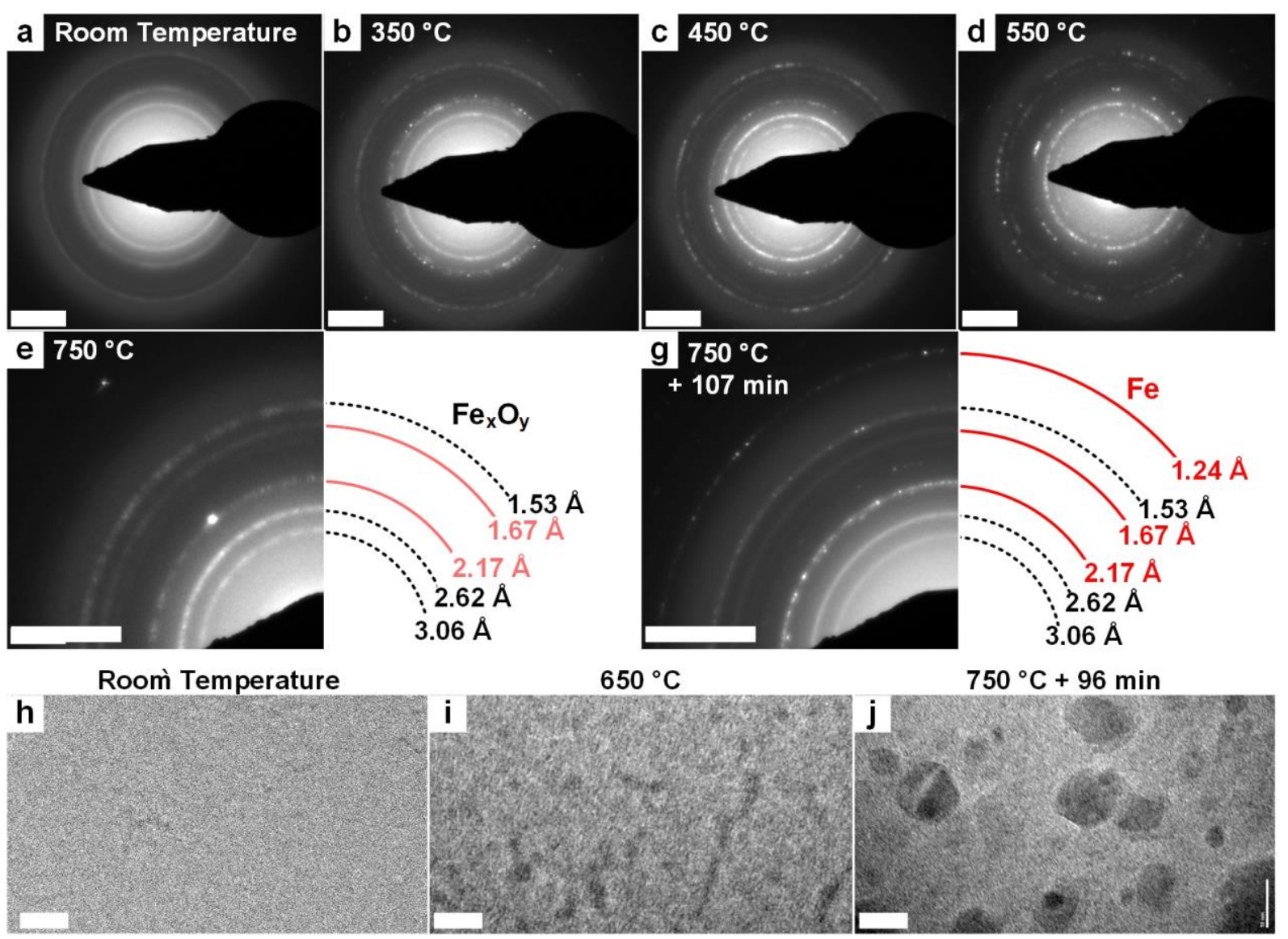

594 Figure 2. Catalyst film evolution during annealing (a-g) ED patterns during heating the $595 \quad \mathrm{Fe}_{\mathrm{x}} \mathrm{O}_{\mathrm{y}} / \mathrm{Al}_{2} \mathrm{O}_{3}$ catalyst film in hydrogen, showing the reduction to metallic Fe with extended dwell 596 time at $750{ }^{\circ} \mathrm{C}$, as confirmed by the emergence of the red rings at interplanar spacings that are 597 characteristic of metallic Fe (scale bar: $3 \mathrm{~nm}^{-1}$ ). (h-j) TEM images taken at different 598 temperatures, showing film restructuring during annealing and particle formation by dewetting 599 after 107 minutes at $750{ }^{\circ} \mathrm{C}$ (scale bar: $10 \mathrm{~nm}$ ).

600 

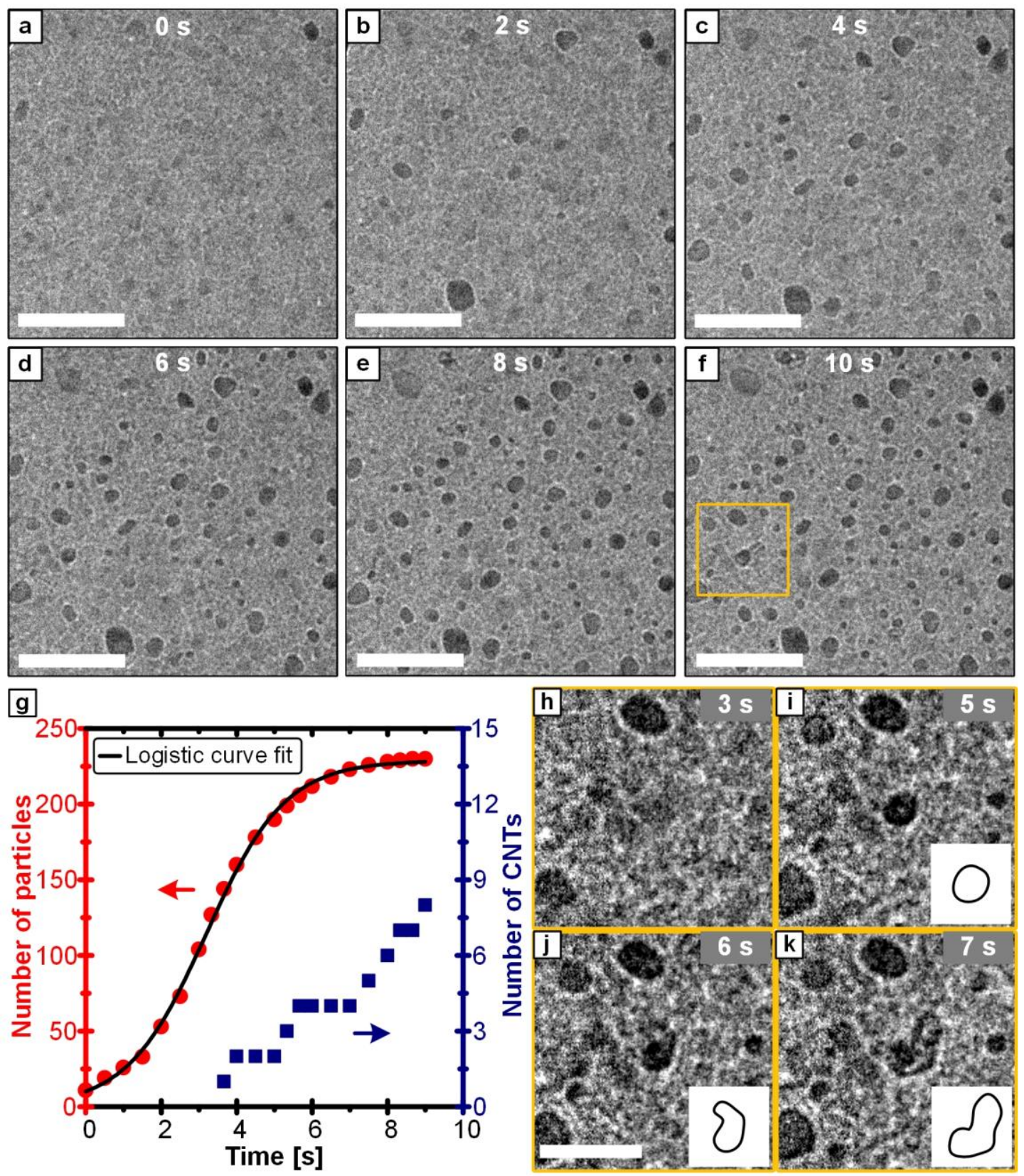

603 Figure 3. Nanoparticle popping and CNT nucleation upon the introduction of $\mathrm{C}_{2} \mathrm{H}_{2}$ at $750{ }^{\circ} \mathrm{C}$. (a-

604 f) TEM images showing the kinetics of forming a nanoparticle population by dewetting. Scale 605 bar is $50 \mathrm{~nm}$. (g) The corresponding number density of particles and CNTs versus time.

606 Nanoparticle popping kinetics exhibits an S-shaped curve, spanning 9 seconds, while CNTs start 607 nucleating after 3.5 seconds of introducing the acetylene precursor, and continue to increase in 608 number beyond 9 seconds. (h-k) Higher magnification TEM images showing one catalyst 609 nanoparticle popping at 5 seconds followed by the nucleation of a CNT. Inset sketches show a 610 schematic of the nucleating CNT. Scale bar is $20 \mathrm{~nm}$. 

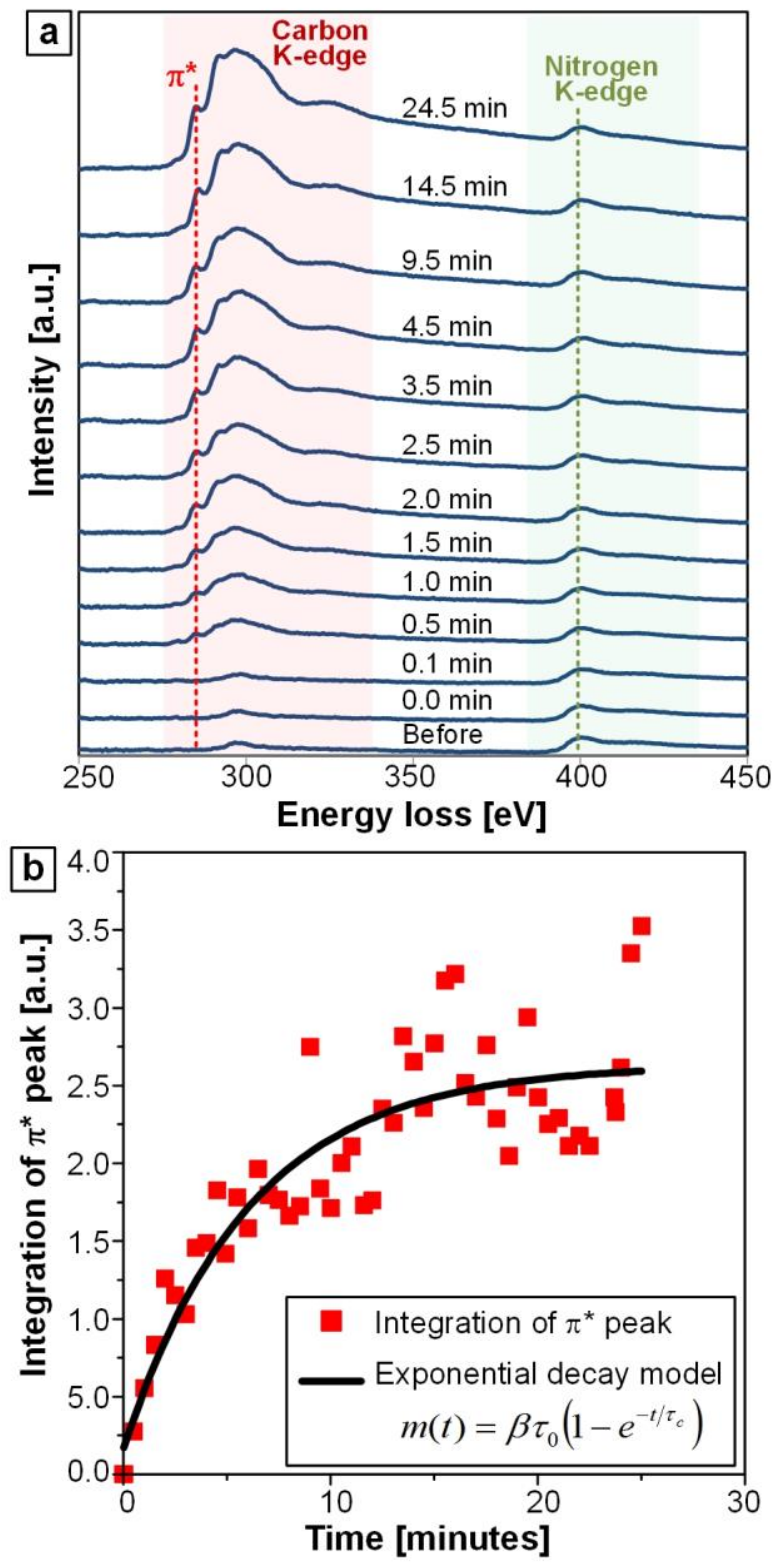

Time [minutes]

612 Figure 4. (a) EELS spectra showing the time evolution of the carbon K-edge and the nitrogen 613 (used as reference from the $\mathrm{Si}_{3} \mathrm{~N}_{4}$ membrane) K-edge structures. (b) Kinetics of surface carbon 614 accumulation in the form of CNTs, calculated by integration under the $\pi^{*}$ peaks (energy width of $6156 \mathrm{eV})$.

616 
$0.8 \mathrm{~min}$.

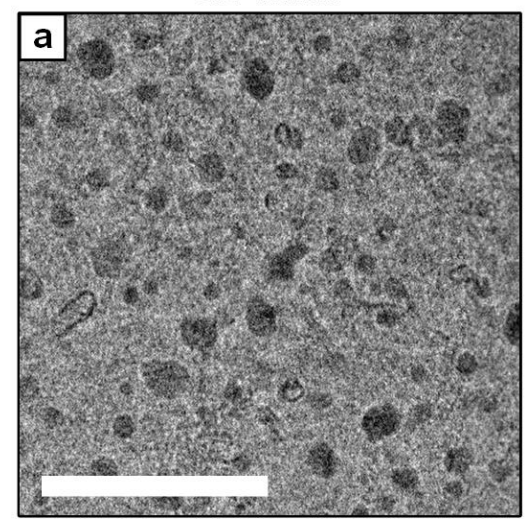

618

619 Figure 5. TEM images showing the crowding of CNTs after (a) 0.8 minutes, (d) 7.5 minutes , 620 and (f) 27.6 minutes of $\mathrm{C}_{2} \mathrm{H}_{2}$ introduction, respectively. Scale bar is $50 \mathrm{~nm}$.
$27.6 \mathrm{~min}$.
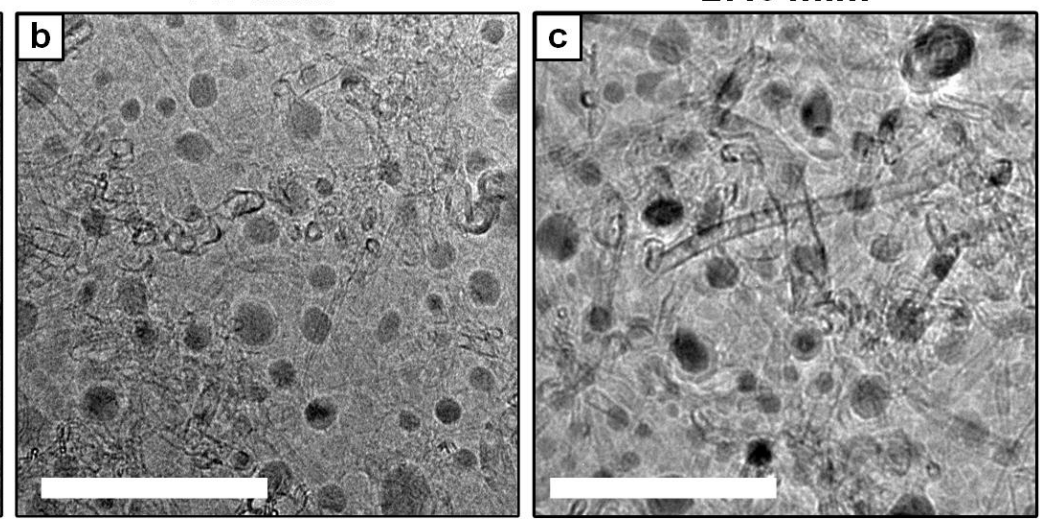

621

622

623 

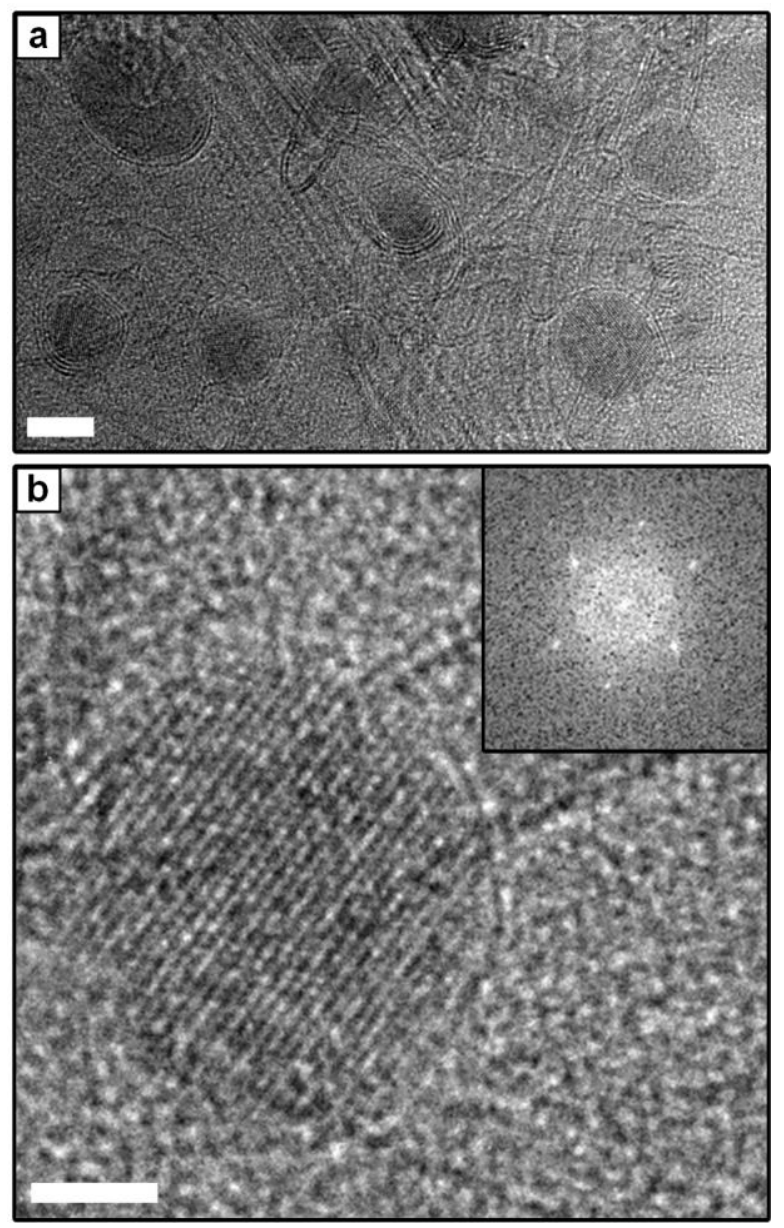

625 Figure 6. (a) In situ TEM images after growth termination, showing that most of the catalyst 626 nanoparticles (both those that grew CNTs and those that did not) are generally encapsulated in a 627 graphitic cage. (b) HR-TEM of one encapsulated nanoparticle, identified as an iron carbide 628 phase $\left(\mathrm{Fe}_{3} \mathrm{C}\right)$. Scale bars are $5 \mathrm{~nm}$ in (b) and $2 \mathrm{~nm}$ in (c). Inset in (c): FFT of the HR-TEM 629 image. 


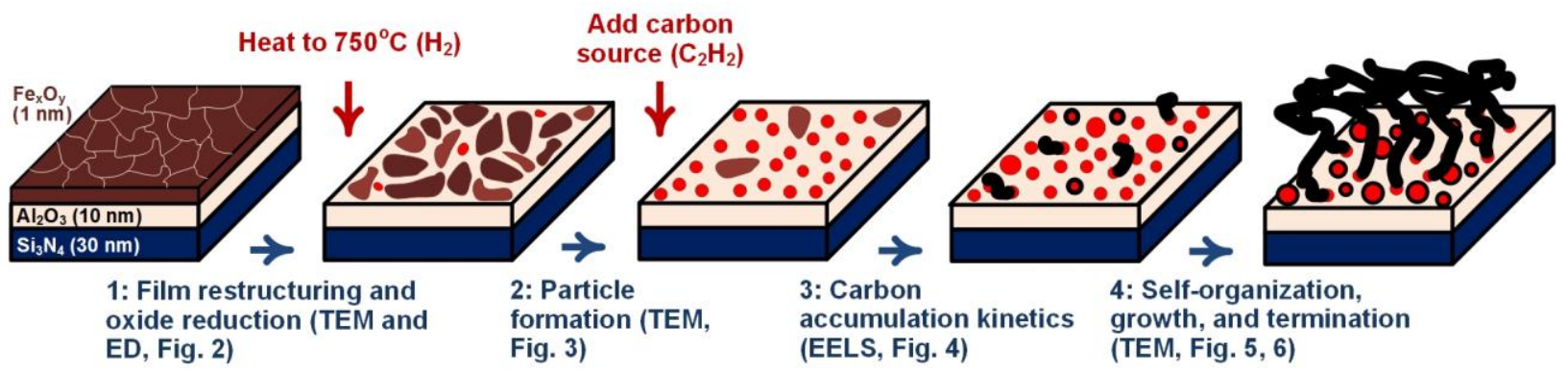

632 Figure 7. Schematic showing the successive stages of nucleation, self-organization, growth, and

633 deactivation of a CNT forest, which are examined in real time at low pressure inside the E-TEM. 
635 TOC Figure

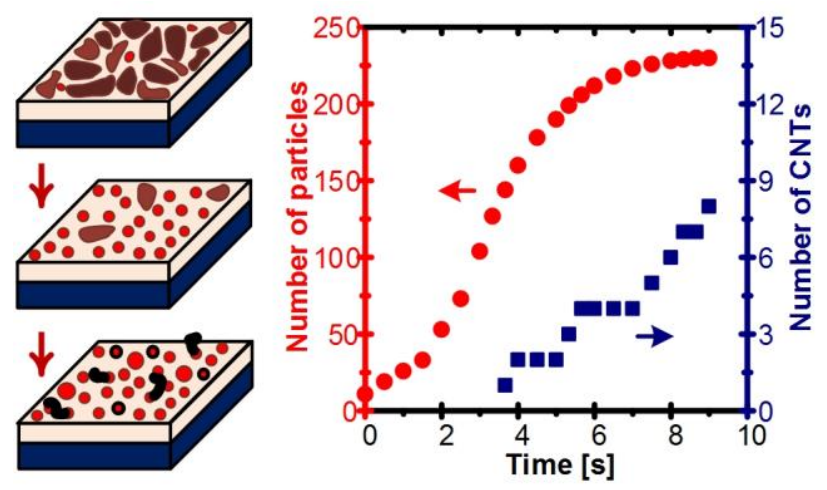

636 